\title{
PORTS' STRUCTURAL AND OPERATIONAL BENCHMARK: METHODOLOGY AND APPLICATION TO THE MEDITERRANEAN BASIN
}

\author{
CRISTIANO MARINACCI, ROSA ALESSANDRA POLO, STEFANO RICCI \& LUCA RIZZETTO \\ Sapienza University of Rome - DICEA, Italy
}

\begin{abstract}
Starting from morphology and equipment, a synthetic method able to provide indicators representing the ports' performances was setup. The knowledge background, built on cartography, statistical data, port master plans and sectorial researches, required important efforts in terms of integration and homogenisation. The method's development is based on a survey of the Mediterranean basin, progressively identifying a sample of ports by additive selection criteria, including geographical location, the layout's morphology, traffic typologies and consistent data availability. A set of indicators characterising the ports' performances allows benchmarking and matching to derive useful design and operational feedback. The achieved results include homogeneous indicators for dimensions, equipment and performances, useful for design and planning purposes, operational checks, identification of bottlenecks and project needs. The extension of the sample (39 case studies in the Mediterranean basin) encompasses the values of results, exposed in thematic maps and diagrams dealing with wharfs' extension vs. sea depth and basin surface, average length of route, the docks' density, ship turnover rates, productivity index, docks utilisation and approaching time. Moreover, the global operational capacity and the related present utilisation rate was calculated, taking into account the internal routes' network, compatibility among routes, manoeuvring times and distribution of traffic by route.

Keywords: transport, navigation, port, operation, capacity, benchmark, Mediterranean.
\end{abstract}

\section{INTRODUCTION}

In an International scenario where production and distribution are worldwide globally integrated, the maritime sector is increasingly playing the role of key ring of the integrated logistic chain [1].

In such a competitive environment, the ports are required to systematically monitor their activities, check their performances and their ability to satisfy the market demand.

Nevertheless, the rich and diversified literature is mainly concentrated on economic aspects, volumes of traffic and effectiveness of loads handling, with minor focus on effects of geography (positive or negative dynamics of locations) and seaside operation (traffic congestion and possible fluidisation measures).

The expansion of maritime flows is today not characterised by a parallel enlargement of the amount of called ports.

Indeed, the big ship-owners companies base their success mainly on economy of scale factors, achieved by the increase of ships' dimensions and the selection of a limited set of ports equipped to host them (length and draught) and manage in the fastest way their loading and unloading.

Meanwhile, in such rigid constraints, the effective management of seaside operation, which is required to prevent congestion and avoid any kind of unproductive time, also plays a key role.

In this framework, the objective of the present research is to identify and propose a systematic quantitative approach to assess and benchmark structural and operational features of ports affecting their service capacity towards ships. 
The systematic evaluation of this capacity represents a primary parameter, both for design and operation of ports and allows identifying possible bottlenecks and effects in terms of delays and economic consequences of congestion.

The main investigated questions are:

- Geographical and morphological factors influencing the port operation (e.g. effects of layouts on operational time);

- Mechanisms to manage the operation influencing the delays generation.

In this respect, the choice to approach the problem with a typically bottom-up method, required to collect a large and as much as possible homogeneous set of data.

For Europe, maritime transport has been a catalyst for economic development and prosperity throughout its history.

Maritime transport enables trade and contacts between all European and world nations: it ensures the security of supply of energy, food and commodities and provides the main vehicle for European imports and exports to the rest of the world.

One of the European Commission's objectives is to protect Europe with very strict safety rules preventing sub-standard shipping, reducing the risk of serious maritime accidents and minimising the health and environmental impact of maritime transport.

The European Commission's strategic goals and recommendations for the EU had been set out in 2009 in the Maritime Transport Policy until 2018.

\section{DATA COLLECTION TOWARDS AN OPERATIONAL PORTS' ATLAS}

Starting from morphology and equipment, a synthetic method able to provide with indicators representing the ports' performances was setup.

The collection included data about:

A. Layout and geometrical features: typologies and distribution of basins, extension of waters, length and specialisation of quays, water's depth, number and dimension of evolution's basins, width of internal and external channels, availability of nautical services;

B. Traffic: yearly, monthly and daily data;

C. Nautical accessibility: yearly period in which the seaside accessibility is free, despite of waves, streams, tides, wind or ports schedule itself;

D. Port rules and regulations: normative for entering and priority, allowed speed, separation scheme and general safety rules.

The database includes the entire Mediterranean basin, encountering mainly homogeneity problems due to typical regional features of many ports.

The main rationales of the database building are the following:

A. The layout and geometrical features allow to fill in a port's descriptive sheet (ports atlas), including main characteristics useful to comparison and benchmarking, as well as to feed the capacity models.

B. The yearly traffic by categories provides with an estimation of the global activity of the port, the monthly traffic lets emerge the possible seasonal trends, as well as the daily ships' planning is the key information to estimate the capacity and its rate of occupancy.

C. The nautical accessibility allows calculating the expected delays for ships during temporary port operation suspensions. 
D. The port rules and regulations are mainly useful to take into account traffic priorities:

a. Departures before arrivals,

b. Military ships before RO-PAX and cargo.

Moreover, depending upon features of basins and ships themselves, the speed must be not too high to avoid collisions during manoeuvres, but not too low to let the rudder ensure the highest manoeuvrability.

Finally, the separation schemes prevent conflicts during manoeuvres, particularly under severe weather conditions.

The data sources include cartography, statistical data, port master plans, sectorial researches, required important efforts in terms of integration and homogenisation.

The method, validated by a survey extended to the Mediterranean basin, progressively identified by additive selection criteria, setup a set of indicators characterising ports' performances, benchmarked and matched each other to derive useful design and operational feedback.

The investigations collected information from the following sources:

- Port authorities;

- Harbourmasters;

- Governmental bodies;

- Statistical institutes;

- Geographical institutes;

- European Union;

- Other studies and researches [2]-[4].

The Mediterranean Sea is a closed basin, with a wide variation of latitude and gates at Suez and Gibraltar, merging three continents and 20 countries, with various socio-economic conditions but a common market.

Therefore, the sample for the investigation results strongly variegated and initially composed by 51 ports over 16 countries, later reduced, due to data availability constraints, to 37 ports over 15 countries only (Fig. 1).

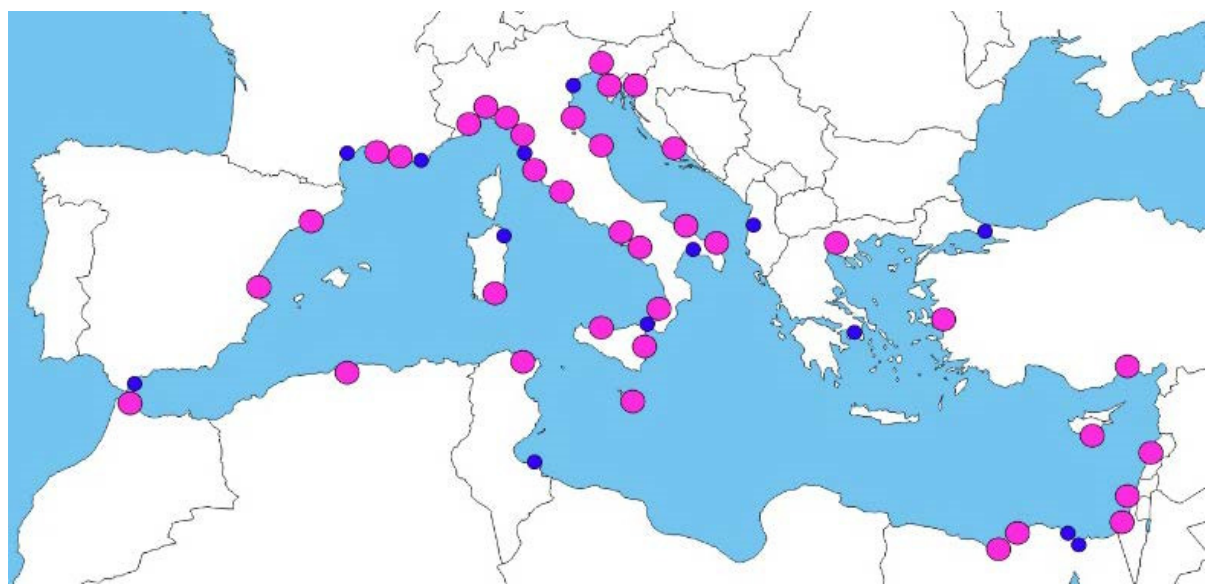

Figure 1: Final sample of investigated ports (highlighted in pink) and set of ports excluded due to data unavailability (highlighted in blue). 
For each port, the data has been homogenised and synthetically stored in sheets, including maps, tables and diagrams: an example for the port of Marseille is in Figs 2 and 3 and Table 1. Similar outputs are available for all the investigated ports.

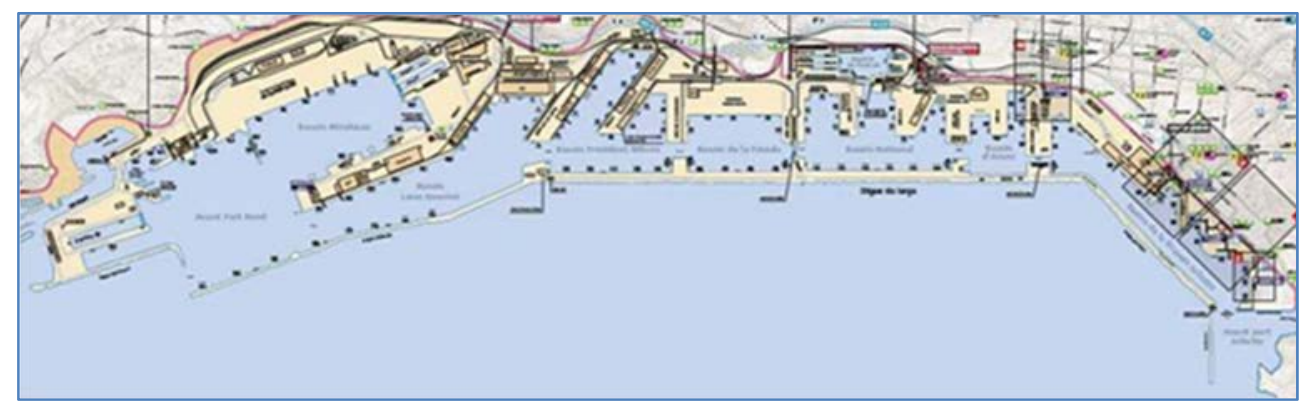

Figure 2: Port of Marseille: layout.

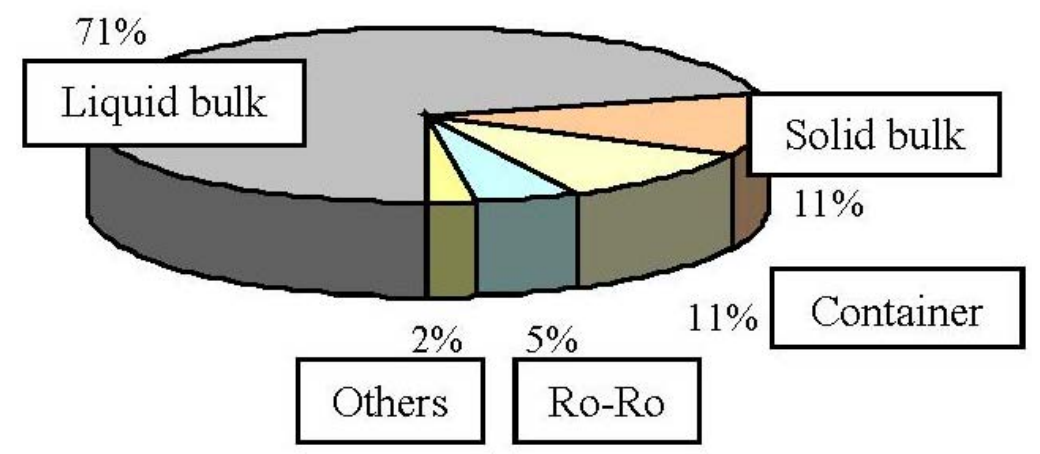

Figure 3: Port of Marseille: traffic distribution.

Table 1: Port of Marseille: characteristics of quays.

\begin{tabular}{|l|c|c|c|c|}
\hline \multicolumn{1}{|c|}{ Basin } & Quay & Min Depth [m] & Max Depth [m] & Length \\
\hline Gourret & $002-008$ & 9,60 & 11,00 & 903 \\
\hline Wilson & $009-025$ & 9,00 & 11,00 & 2034 \\
\hline Pinede & $026-040$ & 8,00 & 10,30 & 1388 \\
\hline National & $041-048$ & 6,00 & 9,00 & 110 \\
\hline Sud Roro & $050-058$ & 7,20 & 9,00 & 943 \\
\hline Arenc & $059-068$ & 6,10 & 7,80 & 905 \\
\hline Grande Joliette & $069-096$ & 6,90 & 7,90 & 2943 \\
\hline Digue du Large & $109-131$ & 3,50 & 11,00 & 3977 \\
\hline Avamport Nord & $143-148$ & 4,00 & 10,00 & 1121 \\
\hline Mirabeau & $150-163$ & 8,90 & 14,40 & 1741 \\
\hline Leon Gourret & $181-186$ & 12,90 & 13,00 & 970 \\
\hline Radoub & F01-F09 & 4,50 & 11,70 & 1882 \\
\hline Radoub & QFAB-QMD3 & 4,40 & 5,00 & 253 \\
\hline
\end{tabular}




\section{METHODOLOGICAL APPROACH}

The method applied for the analysis includes the calculation of synthetic indicators, expressive of present and potential performances of the ports and useful to organise an effective benchmarking among them.

In the literature a large set of studies dealt with the selection of the most effective set of indicators for ports benchmarking both for operational [5]-[7] and economic [8]-[10] performances.

The indicators proposed in the present study, differentiate themselves from the state-of-the-art, aiming to represent synthetically a large set of operational ports performances; therefore, they articulate into the levels defined below.

- Level 1: primary indicators representing the key port's performances:
A. Length of quays,
B. Number of quays,
C. Surface of port's basin,
D. Water's depth,
E. Ships' movement in the reference year,
F. Length of approaching channel,
G. Maximum speed allowed along the approaching channel,
H. Average length of internal routes,
I. Volume of handled goods in the reference year;

- Level 2: secondary indicators, calculated basing on primary indicators, finalised to benchmarking and other comparative analyses:
A. Length of quays by classes of water's depth;
B. Use of quays: yearly ships' movements / length of quays;
C. Density of quays: number of quays/surfaces of port's basin;
D. Extension of quays: length of quays / surface of port's basin;
E. Exchange rate: yearly ships' movements / number of quays;
F. Port's productivity: yearly volume of handled goods /length of quays;
G. Approaching time to port mouth: length of approaching channel / maximum speed allowed along the approaching channel;
H. Extension of internal routes: average length of internal routes / surface of port's basin.

In addition to the indicators above, a specific focus is on the seaside operation; with the research of the maximum ships' flow (capacity) compatible with safety rules and the present utilisation degree.

The method [11], [12] is based on the assessment of the shared resources generating potential conflicts and corresponding queuing processes, to manage in order to ensure a reasonable quality of service.

In the framework of the large literature dealing with ports capacity, the chosen method is able to manage dynamic capacity calculation taking into account of movements directed/generated to/by all terminals and docks, whereas the most consolidated methods and simulation models, mainly deal with static capacity of single terminals and/or docks' occupancy [13], [14].

In this respect, critical standards and features are mainly the separation rules along the approaching routes and the port's basin morphology, managed by the method in terms of compatibility among movements conditioning the capacity itself. 
The model is basing on the seaside schematisation of ships routes from port mouth to quays and back, which may be partially or completely independent.

Therefore, the intermodal equipment and the single terminal operation is not relevant for the global approach, which is willing to assess capacity and utilisation in a global and synthetic approach.

Indeed, the main factors affecting the capacity are the time distribution of entering and exiting movements to/from the port and related assignment to quays as well as the basin's topology defined by quays and mouth location.

To achieve high generality, the model approach is basing on a constant probability for the arrivals: the number of movements per route is representing the demand.

This condition is equivalent to an array $P$, with dimensions corresponding to the number of the routes in the terminal and single elements pi defining the number of movements on each route in the reference time $T$.

The analysis of the terminal morphology allows defining routes and their reciprocal compatibility/incompatibility represented in a square matrix (compatibility matrix) $C=P x P$, with each element $c_{i j}$ representing that condition.

The possible relationships are:

- Incompatibility between two routes due to:

a. Common final/initial sections,

b. Common middle sections,

c. Same path but opposite versus;

- Compatibility between two routes without common sections, where ships can run simultaneously.

The proposed approach allows calculating the average number of possible simultaneous movements $\mathrm{n}$ by taking into account the compatibility of the routes and their frequency of utilisation:

$$
\overline{\mathrm{n}}=\frac{\mathrm{N}^{2}}{\sum_{\mathrm{ij}} \mathrm{m}_{\mathrm{ij}}},
$$

where:

- $\quad m_{i j}=p_{i} \times p_{j}$ if $i$ and $j$ are incompatible;

- $\quad m_{i j}=0$ if $i$ and $j$ are compatible.

In a similar way, the average utilisation time of the terminal is:

$$
\bar{t}=\frac{\sum_{i j} m_{i j} \cdot t_{i j}}{\sum_{i j} m i_{j}}
$$

where $t_{i j}$ is the time during which the route $\mathrm{j}$ may not be run because a ship is moving on the route $i$ (interdiction time) and $N$ is the total number of movements during $T$.

The total occupation time is:

$$
B=\frac{N}{\bar{n}} \cdot \bar{t}
$$


In order to take into account the waiting situations due to simultaneous arrivals on incompatible routes, it is possible to calculate the delay imposed by the $p_{i}$ movements on the $p_{j}$ movements because of the interdiction time $t_{i j}$ :

$$
\mathrm{rij}_{\mathrm{ij}}=\frac{\mathrm{p}_{\mathrm{i}} \cdot \mathrm{p}_{\mathrm{j}} \cdot \mathrm{t}_{\mathrm{ij}}{ }^{2}}{2 \cdot \mathrm{T}} .
$$

These parameters allow the comparison between the total port's utilisation time, including the delays, and the reference time.

The utilisation rate with reference to the regular running on the routes only is:

$$
U_{R}=\frac{B}{T} \text {. }
$$

Alternatively, to the total time, including the delays, as:

$$
U_{T}=\frac{B+R}{T},
$$

where:

$$
R=\sum_{i, j} R_{i j}
$$

Such method is well representing both:

- High frequency of arrivals in the peak periods;

- Typical database in the planning phase, when detailed information on future ships scheduling cannot be available.

\section{RESULTS AND FINDINGS}

\subsection{Rationale}

The achieved results include homogeneous indicators for dimensions, equipment and performances, highly reliable thanks to the extension of the sample (39 case studies):

- For design and planning purposes;

- For operational check, identification of bottlenecks and project needs.

Moreover, the global operational capacity and the related present utilisation rate is calculated taking into account internal routes' network, compatibility among routes, manoeuvring times, distribution of traffic by route.

\subsection{Primary indicators}

The primary indicators are summarised in comparative diagrams: an example is in Fig. 4 with reference to the length of the quays.

The extension of basins is synthetically represented in Fig. 5, reflecting the classification into dimensional classes, with $11 \%$ only associated to the largest one (over $500 \mathrm{ha}$ ).

Finally, the entity of seaside traffic volumes allows the classification of ports into clusters, with $11 \%$ of them managing more than 10,000 movements/years (Fig. 6). 


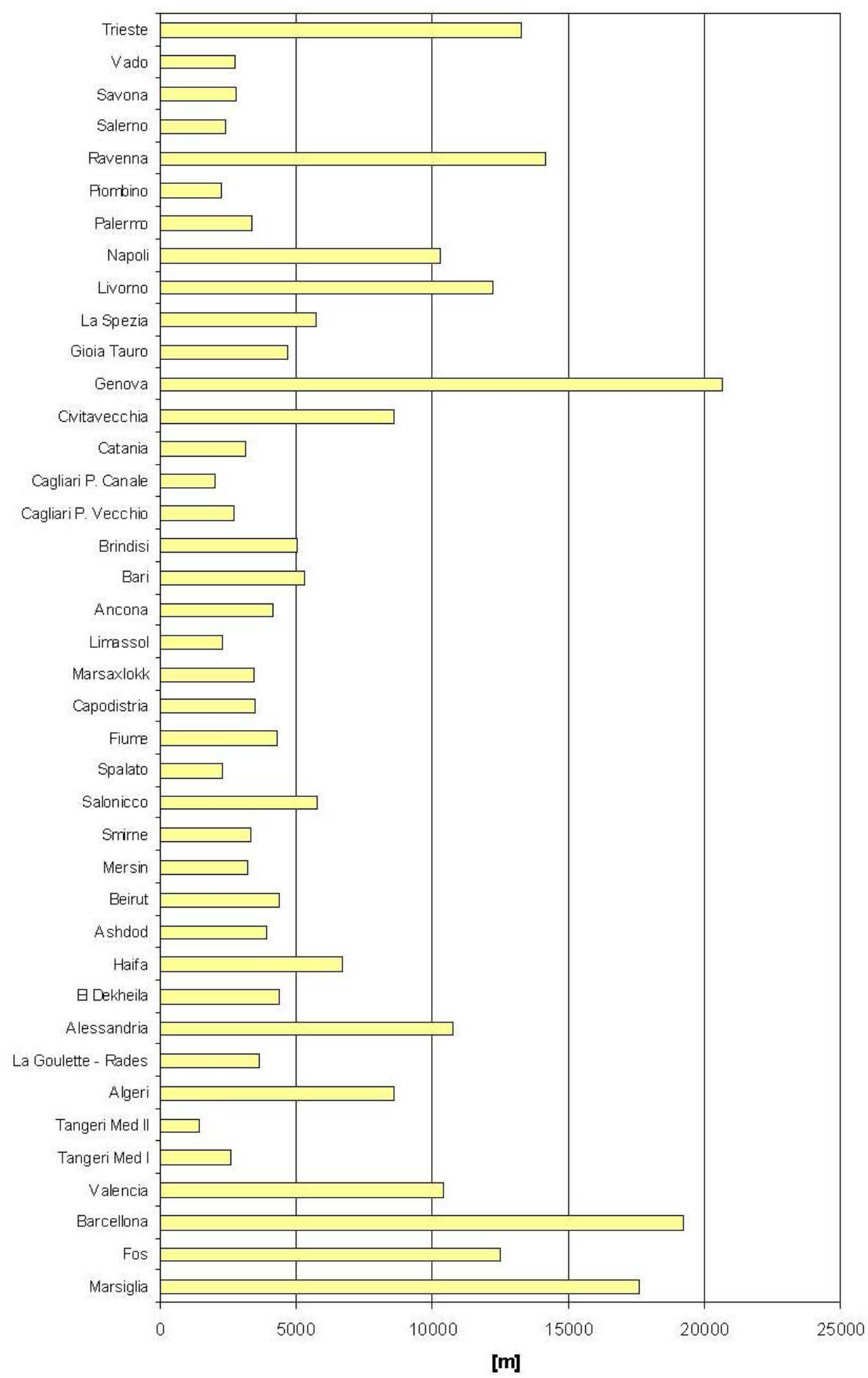

Figure 4: Benchmarking of ports by length of quays (Indicator Level $1-\mathrm{A}$ ). 


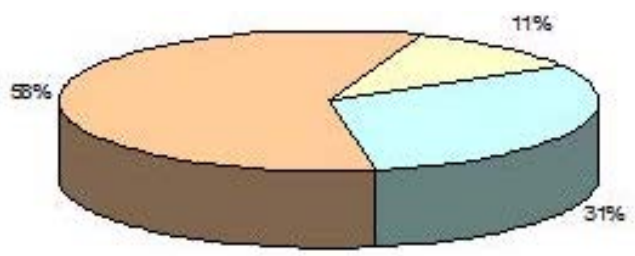

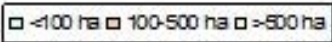

Figure 5: Classification of ports' basins by dimension (ha) (Indicator Level 1 - C).

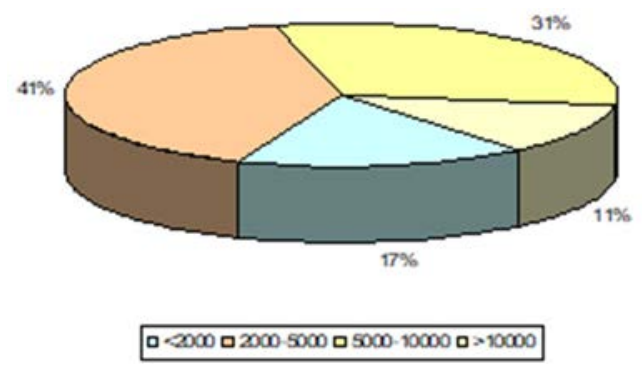

Figure 6: Classification of ports' basins by ship movements (movements/year) (Indicator Level $1-\mathrm{E})$.

\section{CONCLUSIONS}

The methodology setup in the study demonstrates to be able to provide a quantitative assessment of morphological and dimensional aspects of ports, to enrich the most frequently used purely stochastic parameters as handled tonnes or number of TEUs.

Indeed the infrastructural features combined with the offered technical services (pilotage, manoeuvres, etc.) are essential to express reliable indicators of seaside port capacity.

Moreover, the research work succeeded to reach the following relevant objectives:

- Homogeneity of database ensuring good comparative attitude of the methodology;

- Extension of the database ensuring the statistical correlation of indicators and average relationships between characteristic parameters;

- Dual possibility to apply the method both to design new ports (dimensions, equipment, etc.) as well as to assess the performances of existing infrastructures (residual capacity, bottlenecks, etc.);

- Capability to provide synthetic, though reliable, results with a limited amount of input data;

- Possibility to assess globally the performances of a system of ports for potential distribution and re-allocation of traffic.

\section{REFERENCES}

[1] UNCTAD, Review of Maritime Transport, United Nations Publication: New York and Geneva, 2013. 
[2] Lupi, M., Danesi, A., Farina, A. \& Pratelli, A., Maritime Container Transport in Italy. Study on Deep and Short Sea Shipping Routes Departing from the Main Italian Ports and on Rail Modal Shares. IF-Ingegneria Ferroviaria, 5, pp. 409-446, 2012.

[3] National Geospatial-Intelligence Agency, PUB. 131. Sailing Directions (ENROUTE) - Western Mediterranean. United States Government: Springfield, 2014.

[4] National Geospatial-Intelligence Agency, PUB. 131. Sailing Directions (ENROUTE) - Western Mediterranean. United States Government: Springfield, 2015.

[5] Dragovic, B., Park, N.K. \& Radmilovic, Z., Ship-berth link performance evaluation Simulation and analytical approaches. Maritime Policy and Management, 33(3), pp. 281-299, 2006.

[6] Kek, C.C., Port Performance Indicators, Transportation, Water and Urban Development Department, The World Bank, Transport No. PS-6, 1993.

[7] Ricci, S., Marinacci, C. \& Rizzetto L., The modelling support to maritime terminals sea operation: The case study of port of Messina. Journal of Maritime Research, 9(3), pp. 39-43, 2012.

[8] Amr, M. \& Amr, A., Seaport management aspects and perspectives: An overview. Proceedings of the 12th Annual Irish Academy of Management Conference, GalwayMayo Institute of Technology, Galway, Ireland, 2009.

[9] Cullinane, K. \& Talley, W.K., Port economics. Research in Transportation Economics, 16, pp. 1-249, 2006.

[10] Marlow, P.B., Measuring lean ports performance. International Journal of Transport Management, 1, pp. 189-202, 2003.

[11] Malavasi, G. \& Ricci, S., The seaside port capacity: A synthetic evaluation model. Maritime Heritage and Modern Ports, I. Marcet, R. Barbe, C. Brebbia \& J. Olivella (eds) WIT Transactions on the Built Environment, vol. 79, WIT Press: Southampton and Boston, pp. 471-480, 2005.

[12] Marinacci, C., Quattrini, A. \& Ricci, S., Integrated design process of maritime terminals assisted by simulation models. International Conference on Harbour, Maritime and Multimodal Logistics Modelling and Simulation, 1, pp. 190-201, 2008.

[13] Kia, M., Shayan, E. \& Ghotb, F., Investigation of port capacity under a new approach by computer simulation. Computers and Industrial Engineering, 42, pp. 533-540, 2002.

[14] Munisamy, S., Timber terminal capacity planning through queuing theory. Maritime Economics \& Logistics, 12, pp. 147-161, 2010. 